\section{HPV vaccine introduction at the local level in a developing country: attitudes and criteria among key actors}

\author{
Introducción de la vacuna contra el VPH en niveles \\ locales de un país en vías de desarrollo: actitudes \\ y criterios de actores clave
}

\author{
1 Instituto Nacional de \\ Cancerología, Bogotá \\ Colombia. \\ Correspondência \\ M. Piñeros \\ Instituto Nacional de \\ Cancerología. \\ Calle 1, n. 9-85, Bogotá \\ DC-001, Colombia. \\ mpineros@cancer.gov.co
}

\begin{abstract}
In most developing countries, HPV vaccines have been licensed but there are no national policy recommendations, nor is it clear how decisions on the introduction of this new vaccine are made. Decentralization processes in many Latin American countries favor decision-making at the local level. Through a qualitative study we explored knowledge regarding the HPV vaccine and the criteria that influence decision-making among local health actors in four regions of Colombia. We conducted a total of 14 in-depths interviews with different actors; for the analysis we performed content analysis. Results indicate that decisionmaking on the HPV vaccine at the local level has mainly been driven by pressure from local political actors, in a setting where there is low technical knowledge of the vaccine. This increases the risk of initiatives that may foster inequity. Local decisions and initiatives need to be strengthened technically and supported by national-level decisions, guidelines and follow-up.
\end{abstract}

Papillomavirus Vaccines; Uterine Cervical Neoplasms; Health Policy

\author{
Marion Piñeros 1 \\ Carolina Wiesner 1 \\ Claudia Cortés 1 \\ Lina María Trujillo 1
}

\section{Introduction}

The development of the human papillomavirus (HPV) prophylactic vaccines marks a significant scientific and technological breakthrough in the fight against cervical cancer. However, transferring the efficacy of results into effectiveness in terms of reducing the burden of disease in the target population, involves the delivery of the vaccine in comprehensive public health programs 1,2. Deciding whether a new vaccine like the HPV vaccine warrants its inclusion in the national immunization program, or even in local immunization programs, involves a process that does not seem to be straightforward.

In order to assist decision-making on new vaccines, the World Health Organization (WHO) has developed a framework that poses a series of questions in the form of a checklist, helping to provide answers the following considerations: whether the disease is a public health burden; whether immunization is the best control strategy; if the existing immunization programme is working well enough to add a new vaccine; estimate the net impact of the vaccine; whether it is a good investment in terms of cost effectiveness; how the vaccine will be funded and how the addition of the vaccine will be implemented ${ }^{3}$. These aspects have been considered in the Pan American Health Organizations' (PAHO) guidelines for the introduction of new vaccines, whereby the criteria for the decision-making itself are divided 
into two broad categories: (a) political and technical criteria and (b) feasibility criteria 4 .

Recently, a systematic literature review of the existing support on decision aids for new vaccine introduction has proposed a stepwise approach, providing a rational approach to decision-making that might facilitate the process. Additional relevant issues that are considered within this approach are the ethical and equity considerations 5 .

At present, many developed countries have already decided to introduce the HPV vaccine into their regular immunization programmes. In contrast, only a few developing countries where cervical cancer constitutes a significantly greater public health problem - have already made such a decision. One might argue that cost is the determining factor for this difference, according to the history of the introduction of the hepatitis B vaccine, where it took low income nations twice as long to achieve implementation as it did for high income nations 6 . Nevertheless, it has been shown that there are other factors determining the speed at which a new vaccine is introduced, such as the existence of pilot projects, the scientific evidence regarding efficacy, political pressure and the role of scientific associations 6 .

Health reforms in many Latin American countries have been accompanied by decentralization processes which favour local decision making. In the current Colombian health system, local level administrations, like districts or municipalities that have attained a certain degree of economic development, can exercise autonomy over several aspects of public health decision making. This includes the acquisition of new vaccines that have not yet been included in the national immunization program.

The aims of this study were to explore, in various districts in Colombia among local health decision makers, the criteria and factors that are being considered for deciding on the introduction of the HPV vaccine. Results will lead to a better understanding of the issues surrounding the decisions on the introduction of the HPV vaccine, particularly in a Latin American setting.

\section{Materials and methods}

The present results are part of a broader study, entitled Knowledge and Acceptability of the HPV Vaccine among Parents of Adolescents, Physicians and Decision Makers in Colombia that was approved by the National Cancer Institute Ethical Committee in September 2007.
We developed an exploratory, qualitative study in four Colombian cities, selected to exemplify the socio-cultural diversity of the nation, thus providing an opportunity to come into contact with different attitudes on HPV vaccine acceptance. Two cities were selected in the Andean region: Bogotá, a megalopolis and Manizales, an intermediate, provincial capital. They were chosen as examples of two areas that have relatively well developed economies and the second one, known for a more conservative and religious culture. The other two cities - Arauca, a remote, small city on the Colombian-Venezuelan border with high cervical cancer mortality and Cartagena, a tourist hub on the Caribbean coast - characterize cities that are far less developed.

Regarding health decision making the aim was to explore how local health decision makers deal with HPV vaccine introduction, and the most important factors that they are considering for determining their final decisions.

In the four cities, we conducted semi-structured interviews with the following local health authorities: the general health secretary (the maximum authority), the head of the public health department, and the professionals responsible for sexual and reproductive health and immunization programs. As such, in each city, four interviews should be completed, giving a total of 16 interviews.

\section{Data collection}

Data collection took place between February and August 2008, which was one and two years later, respectively, after the two HPV vaccines had received licensure in Colombia.

The decision-makers to be interviewed were first contacted by phone, and a request was made for a personal appointment. They were informed that the purpose of this meeting would be to discuss a project related to cervical cancer control. However, in order to avoid inducing biased responses, no specific mention of the HPV vaccine was made during this initial phone conversation.

During the personal interview, the interviewer explained the objectives of the project, provided assurance of confidentiality and voluntary participation, and received verbal consent to record the interview.

Interviews took place using a guideline that covered the basic categories recommended by the PAHO 4: burden of disease related to HPV; perception of the HPV vaccine as a priority and plans developed regarding its introduction; knowledge on the HPV vaccines, their efficacy and information sources; challenges facing HPV 
vaccination; cervical cancer screening activities; and programmatic and feasibility aspects of HPV vaccine introduction.

\section{Respondents}

A total of 14 interviews were carried out, in the following form: General Health Secretary (3), Directors of the Public Health Divisions (3); Coordinators of Sexual and Reproductive Health Programs (4); Coordinators of the Expanded Immunization Programs (4). In one city it was not possible to make an appointment with the General Health Secretary and in another city the post of the director of the Public Health Division was vacant at the time of the visits. The interviews lasted for 30 to 45 minutes. They were tape recorded, then transcribed verbatim with the addition of observation notes.

\section{Analysis and data quality}

Interview content analysis focused on informants' transcription of verbal responses. The steps involved in content analysis were: open reading, codification, structural analysis, and critical interpretation.

After controlling the quality of the transcription all team members read each text, and analysed the data minutely into significant units. These units were grouped according to pre established and emerging categories identified by a triangulation process among researchers. The structural analysis was accomplished through conceptual and relational maps for each city and regions. Interpretation took into account the categories, the particular context and was contrasted with existing scientific literature.

Interview data quality was ensured by having both an interviewer and an observer present. Information was triangulated through comparisons made with informant groups, with diverse sources (informants and documents), and with the participation of the four researchers. Additionally, the ongoing study took place under the monitoring system of the National Cancer Institute, thus guaranteeing compliance with optimal research standards.

\section{Results}

Overall, the results showed differences between the two most developed and the two less developed cities. According to the analysis, the results are presented highlighting the most relevant categories, which encompassed: perception of disease burden; knowledge of the HPV vaccine and information sources; perceptions of the HPV vaccine as a political priority; constraints and ethical implications. The ethical aspects were an emergent category; programmatic and feasibility criteria hardly were mentioned and the performance of the cervical screening programme was an issue mentioned mainly as concern regarding equity.

\section{Perception of HPV related disease burden}

All interviewees readily agreed that cervical cancer is a major public health problem. Nevertheless, in one city, they mentioned that maternal mortality and adolescent pregnancies represent a significantly greater burden of disease than cervical cancer. No concrete figures on disease burden were exposed, but in one specific case, they referred to in-depth information of very good quality gathered by a pharmaceutical company, that profiled the local situation in a precise form.

In one of the cities, the disease burden of genital warts among the general population and specifically for members of the local armed forces was repeatedly brought up, and the vaccine was viewed as a potential tool for the control of genital warts, as a sexually transmitted disease, rather than for preventing cervical cancer (Table 1, citation 1). Other interviewees expressed their concern that the vaccine as a means for controlling a sexually transmitted disease would protect only for one of the many diseases of this type.

\section{Knowledge of the HPV vaccine and information sources}

In general terms, most of the local decision-makers knew very little about HPV and the HPV vaccine, and even less about the efficacy, security, age and gender of vaccination, the differences of each vaccine on the market, or the need to continue screening (Table 1, citations 2 and 3). One exception was that of the head of one public health department who had taken an active role in developing a HPV vaccine cost-effectiveness study.

In all of the regions, one or more of the interviewees, particularly the highest ranking health authority and the heads of the public health divisions, had been directly contacted by pharmaceutical industry representatives, who figured as their most important and most accessible information source. The interviewees considered the information provided by the manufacturers of the vaccine to be very useful and at the same time praised the scientific events that they sponsored (Table 1, citations 4 and 5). 
Disease burden, knowledge and information sources related to the HPV vaccine among decision makers. Colombia, 2008.

\begin{tabular}{|c|c|c|c|}
\hline Citation & Testimony & Interview & Lines \\
\hline 1. & $\begin{array}{l}\text { "We deal with a very high incidence of genital warts... It's very sad to see the } \\
\text { women who are the partners of these men who take no precautions" }\end{array}$ & 8 & $168-171$ \\
\hline 2. & $\begin{array}{l}\text { "I'm not too well informed about the vaccine... I know about the general } \\
\text { commercial aspect... that it is in the testing stage" }\end{array}$ & 9 & $150-152$ \\
\hline 3. & $\begin{array}{c}\text { "The fact that you can be vaccinated to prevent a cancer appearing is easier that } \\
\text { having a Pap test" }\end{array}$ & 14 & $144-145$ \\
\hline 4. & $\begin{array}{c}\text { "We began to hear about the HPV vaccine last year when representatives of a } \\
\text { pharmaceutical laboratory visited us... we were fascinated... we understand that } \\
\text { the vaccine is excellent" }\end{array}$ & 7 & $72-74$ \\
\hline 5. & $\begin{array}{c}\text { "The pharmaceutical companies have provided us with materials... they've } \\
\text { sponsored meetings... even scientific events" }\end{array}$ & 6 & $114-115$ \\
\hline 6. & $\begin{array}{c}\text { "The information provided by the pharmaceutical companies is not what you } \\
\text { need... you have to find out for yourself what the negative side effects might } \\
\text { be... because they are never going to tell you" }\end{array}$ & 1 & 129-132 \\
\hline 7. & $\begin{array}{c}\text { "Each company has to speak in glowing terms about its product... but what we } \\
\text { really want is to be able to weigh the information... that's why we would like to } \\
\text { have other people in to orient us" }\end{array}$ & 7 & $118-120$ \\
\hline
\end{tabular}

In contrast, some interviewees declared that the pharmaceutical companies' economic interests could unduly influence the information that they provided, resulting in its being biased and possibly unreliable. Nevertheless, these interviewees recognized that the appearance of outside pressure groups had motivated them to seek more information on HPV and to take the opinions of third parties into account (Table 1, citations 6 and 7).

In general, the professionals responsible for the Expanded Immunization Program were the most concerned about the characteristics of the vaccine, aspects that were scarcely, if at all, mentioned by the other actors.

\section{Perceptions of the HPV vaccine as a political priority}

Some interviewees recognized the vaccine as a scientific breakthrough, as a good solution for cervical cancer control and as one that should be implemented locally as soon as possible, even without waiting for national governmental recommendations to be issued. However, other interviewees expressed some degree of scepticism towards the benefits of the HPV vaccine, still preferring to rely on improved screening programs to guarantee early cervical cancer detection, and expressing the belief that a HPV vaccination program should be under the exclu- sive direction of the National Ministry of Health (Table 2, citation 1).

In both cities, it was also apparent that the male mayors and their spouses - or "first ladies", who are sometimes referred to as "agents of social change" - had found in the HPV vaccine a worthy cause, and had consequently applied pressure on health sector decision makers to include the vaccine in local vaccination initiatives. As a result, in these two cities concrete proposals for HPV vaccine implementation were mentioned (Table 2, citations 2 and 3). In one of these cities, the interviewees stated that their proposal could help "to find the appropriate way to establish a public policy on vaccine implementation”.

In the two more underdeveloped cities, the decision makers agreed that Colombia was not yet ready for massive HPV vaccine implementation due to a lack of cost-effectiveness studies, and to the existence of even more pressing problems that should be solved first.

\section{Constraints and ethical implications}

Virtually all the interviewees shared the opinion that the greatest obstacle for HPV vaccine implementation was cost (Table 3 , citation 1). In two cities, there was notable concern about the time required to lower the cost of the vaccine which would be the only way to make it widely available at the local level. 
Table 2

Perceptions of the HPV vaccine as a political priority, local decision makers. Colombia, 2008.

\begin{tabular}{|c|c|c|c|}
\hline Citation & Testimony & Interview & Lines \\
\hline 1 & $\begin{array}{c}\text { "We have held no discussions on the matter... we comply with the program } \\
\text { guidelines issued by the National Health Ministry regarding the immunization } \\
\text { program" }\end{array}$ & 12 & $21-23$ \\
\hline 2 & $\begin{array}{l}\text { "We have already made the political decision... the mayor and his wife have } \\
\text { expressed special interest on the issue of cervical cancer... they both believe it } \\
\text { is important to get to work on making the vaccine available" }\end{array}$ & 1 & $62-64$ \\
\hline 3 & $\begin{array}{l}\text { "We've been in touch with the mayor's wife... she's been collaborating } \\
\text { with us... she's very concerned about getting the vaccine included in the } \\
\text { department's vaccine program... even before us..." }\end{array}$ & 9 & 184-188 \\
\hline
\end{tabular}

Table 3

Constraints and ethical implications of the HPV vaccine introduction, local health decision makers. Colombia, 2008.

\begin{tabular}{|c|c|c|c|}
\hline Citation & Testimony & Interview & Lines \\
\hline 1 & $\begin{array}{l}\text { "It's very expensive, right? ... It's a vaccine that would be very difficult, if not } \\
\text { impossible to make widely available..." }\end{array}$ & 3 & $36-39$ \\
\hline 2 & $\begin{array}{c}\text { "Our resources are so limited that we have to make very careful selections... } \\
\text { of course... the risk factor is sexual debut... we need to think about the } \\
\text { candidates... maybe prostitutes... the idea is not to focus on prostitutes, but on } \\
\text { their daughters" }\end{array}$ & 7 & $125-135$ \\
\hline 3 & $\begin{array}{l}\text { "We could be causing inequity among the affiliated adolescent population } \\
\text { because the non-affiliated population, which eventually will get the vaccine by } \\
\text { the state, would not be protected... that would not be equitable treatment" }\end{array}$ & 4 & $275-277$ \\
\hline 4 & $\begin{array}{l}\text { "Focusing on the potential recipients and then deciding who gets the vaccine } \\
\text { and who doesn't is a hard job because our budget is not going to cover the } \\
\text { current cost of the vaccine... so, deciding that this woman gets it, but that } \\
\text { woman doesn't is" }\end{array}$ & 3 & 134-137 \\
\hline
\end{tabular}

Interviewees emphasized that the current cost of the HPV vaccine could hold back implementation programs, and mean that it only becomes available to some population groups. In light of this concern, the careful selection of candidates for HPV vaccination was often mentioned as one key decision in any implementation proposal. In one city there was a budget approval that permitted the purchase of 100 vaccines: the population suggested for vaccination was 100 daughters of prostitutes, due to their "high risk profile". Many actors mentioned that necessarily, vaccination strategies should focus on poor women, high risk populations, and women of a reproductive age. Many expressed their doubts regarding equity issues and one interviewee even dubbed the HPV vaccine, "the vaccine of inequality” (Table 3, citations 2, 3 and 4).
In one city there was particular concern regarding the performance of the cervical screening activities in light of the HPV vaccine introduction, arguing that the latter would imply a serious conflict for screening as there wouldn't be enough resources to perform both interventions. Similarly, in another city the possibility of the HPV vaccine introduction raised concerns on insufficient budget to cover concurrent health priorities if the vaccine was introduced. 


\section{Discussion}

This study reveals, above all, how cervical cancer in Colombia, which in the past was not considered a priority by local health professionals 7 , has now become a recognized public health problem.

Undoubtedly, the high profile of cervical cancer in public discourse can largely be attributed to the launching of the HPV vaccine around the world and in Colombia. This event received an enormous boost from the mass media and the manufacturers, which have organized scientific events, information campaigns, as well as marketing strategies aimed at physicians, patients, and decision makers at all levels. The effects of the manufacturers' marketing strategy were clearly visible throughout this study: almost all the decision makers interviewed, particularly those who held the highest positions, had at some time been directly contacted either by representatives of pharmaceutical companies, or by local politicians or their spouses, who expressed an unusually strong interest in cervical cancer and the HPV vaccine. In one African study, decision makers also alluded to the influence that the pharmaceutical companies exert on local politicians ${ }^{8}$. Unfortunately, in the present study important actors, like the majors or their spouses were not approached to examine their motivations regarding introduction of the HPV vaccine. Elsewhere, HPV vaccine marketing strategies have been recognized as unprecedented 9 , pushing even developed countries with low-incidence and mortality for cervical cancer to adopt the vaccine as mandatory 10,11 .

Although almost all the decision makers had been visited by the manufacturers, and had received "useful" information and materials, their knowledge on the vaccine itself and its different aspects was low. This findings contrast with the results of a study where public health decision makers preferred short summaries 12 , as are the characteristics of the industries leaflets. For stakeholders of a higher profile like the public health directors this might be understandable in terms of the time constraints for reading but for more technical profiles like the coordinators of the Expanded Program on Immunisation, the scarce knowledge is surprising. A recent study on public health officers' opinions regarding new vaccines showed how a high proportion of respondents were not satisfied with the information they had on some new vaccines ${ }^{13}$. Although this point was not evaluated in the present study, the absence of information or recommendations from the national governmental level was mentioned in several forms.
In this study, some local actors emphasized the benefits of the vaccine against a sexually transmitted disease, particularly for the prevention of genital warts. At the same time they expressed concern that they had only limited protection against sexually transmitted diseases in general. Undoubtedly, the way in which the HPV vaccine is presented is a matter of debate. Some authors have claimed that presenting the vaccine as an anticancer vaccine has been a marketing strategy for avoiding the sexually transmitted nature of the virus, a theme that causes some unease among the general public and parents 10,14,15; others have concluded that the ability to prevent cervical cancer override the concerns about increased sexual promiscuity 16 and an African study concluded that presenting it as a vaccine against cervical cancer would achieve a better acceptance 8 . The results of the present study involving the physician's perspective also revealed that the vaccine had higher acceptability when presented as a cervical cancer vaccine 17 . There is no evidence that vaccination against STDs increases sexual promiscuity 18 and no doubt that, at least in developing countries, the major impact of the HPV vaccine will be on cervical cancer. Despite this, it does not rule out the need to inform people that HPV infection is acquired through sexual relations.

All the interviewees in this study mentioned cost as the principal obstacle holding up HPV vaccine implementation; this gave rise to proposals of vaccine implementation focused on high risk populations. These proposals should be explored in more detail. If a high risk population refers to a subgroup with higher possibilities of transmission, the proposal ignores the high transmissibility of the HPV virus, and the fact that almost every person with sexual intercourse will acquire the infection ${ }^{19}$. Furthermore, focusing on high risk populations also denies the minimum vaccine coverage needed for the control of a vaccine preventable infection. A high-risk population approach was used at the beginning of the introduction of the hepatitis $\mathrm{B}$ vaccine, and showed that it did not lead to reduced incidence of hepatitis B ten years later 20 . On the other hand, if the high-risk population refers to a population with higher cervical cancer mortality, eg. developing countries and poorer populations, it also conveys ethical implications as such an approach reaches only partial populations. This could be overcome using a step-wise approach as has been proposed formerly with the hepatitis B vaccine introduction in the Gambia ${ }^{21}$. Reducing inequity has been an argument of various proponents of mandatory vaccination in some states of the United States, 
though mandatory vaccination affects other ethical aspects like personal autonomy 22,23,24.

In the present study it became clear that those local decision makers who were firmly in favour of HPV vaccine introduction had reached their decision based more likely on pressure from political figures than on sound scientific evidence. The high "political" pressure associated with the low degree of scientific and technical knowledge, and the absence of national recommendations regarding the HPV vaccine implies the risk of decisions with serious ethical consequences, as the ones presented. In turn, the high external pressure associated with strong budget constraints increases the risk of having a multitude of minor HPV vaccine implementation initiatives that favour a scenario of "opportunistic vaccination" with foreseeable inequity, as has been highlighted elsewhere 25,26 .

One possible solution to minimize the ethical issues surrounding the limitations of HPV vaccine introduction at the local level, is the establishment of guided pilot projects, oriented to gather contextual scientific evidence; these in turn can contribute to decision making at the national level, as has been the case in middle income countries with the hepatitis B vaccine 6 .

One common denominator in most developed nations where HPV vaccines have received licensure, has been the issuing of technical rec- ommendations soon after the licensure even before making the decision about the introduction of the HPV vaccine 27 . In our understanding only a few developing countries in Latin America where the HPV vaccine has received licensure, have sound national recommendations for its use. As such, the administration of the vaccine, which is initially in the private sector, goes hand in hand with the age recommended in the manufacturers' leaflets rather than with an optimal age from the public health perspective.

Health decentralization policies in Latin America have often proved to produce contrary results, leading to greater health inequity 28 . As such, regarding the introduction of the HPV vaccine, these countries should follow the PAHO recommendations with national, evidence based, decision making 4 . Until national vaccine implementation decisions can be made, it is urgent to provide specific technical recommendations and develop education strategies in order to minimize the risk of initiatives that foster inequity. Local initiatives need to be guided in order to produce sound pilot programs that can be useful for national decision making.

Despite the fact that many interested parties call for quicker decision making in Latin American and Caribbean countries, it is essential that these nations receive expert and technical assistance for the decision making process.

\section{Resumen}

En gran parte de los países en vías de desarrollo, las vacunas contra el VPH tienen aprobación para su comercialización. Sin embargo, no hay recomendaciones y tampoco hay claridad sobre la forma en la que se toman las decisiones para su introducción. La reforma del sistema de salud en muchos países latinoamericanos permite la toma de decisiones en el nivel local. Mediante un estudio cualitativo con actores claves del sector salud en cuatro regiones de Colombia, exploramos el conocimiento sobre la vacuna del VPH y los criterios que influyen en la toma de decisiones. Se realizaron 14 entrevistas en profundidad y análisis de contenido.
Los resultados indican que en el nivel local la toma de decisiones sobre la introducción de la vacuna está determinada en gran parte por la presión ejercida por figuras politicas locales. Esto, sumado a un bajo nivel de conocimiento técnico, incrementa la posibilidad de iniciativas con implicaciones éticas considerables. Las decisiones e iniciativas locales relacionadas con esta vacuna necesitan fortalecerse técnicamente y apoyarse desde el nivel nacional.

Vacunas contra Papillomavirus; Neoplasias del Cuello Uterino; Política de Salud 


\section{Contributors}

M. Piñeros was responsible for the conception and design of the study, information gathering (interviews), analyses and interpretation, drafting of the article; final approval of the version and administration of the project. C. Wiesner and C. Cortés were involved in the conception and design of the study, information gathering (interviews), analyses, critical revision of the article, final approval of the version. L. M. Trujillo carried out information gathering (interviews), analyses, critical revision of the article, and approval of the final version.

\section{Acknowledgments}

We wish to thank all the participating interviewees, Mr. Jaime Ardila for his collaboration in procuring bibliographical materials, and the Program for Appropriate Technology in Health (PATH) for their financial support and collaboration.

\section{References}

1. Clemens J, Brenner R, Rao M, Tafari N, Lowe C Evaluating new vaccines for developing countries. Efficacy or effectiveness? JAMA 1996; 275:390-7.

2. Fedson DS. Measuring protection: efficacy versus effectiveness. Dev Biol Stand 1998; 95:195-201.

3. World Health Organization/Western Pacific Regional Office. Assessing new vaccines for national immunization programmes. A framework to assist decision makers. Geneva: World Health Organization; 2000.

4. Organización Panamericana de la Salud. Guía sobre la introducción e implementación de nuevas vacunas. Washington DC: Organización Panamericana de la Salud; 2007.

5. Piso B, Wild C. Decision support in vaccination policies. Vaccine 2009; 27:5923-8.

6. Munira SL, Fritzen SA. What influences government adoption of vaccines in developing countries? A policy process analysis. Soc Sci Med 2007; 65:1751-64.

7. Wiesner-Ceballos C, Moreno RHM, Piñeros Petersen M, Tovar-Murillo SL, Cendales Duarte R, Gutiérrez MC. Control del cáncer cervicouterino en Colombia: la perspectiva de los actores del sistema de salud. Rev Panam Salud Pública 2009; 25:1-8.
8. Harries J, MoodleyJ, Barone MA, Mall S, Sinanovic E. Preparing for HPV vaccination in South Africa: key challenges and opinions. Vaccine 2009; 27:38-44.

9. Onder RF. HPV vaccine mandates: just say "no" to the "great big public health experiment". Mo Med 2008; 105:8-11.

10. Basu S. Compulsory HPV vaccination. N Engl J Med 2007; 356:1074-5.

11. Wynia MK. Public health, public trust and lobbying. Am J Bioeth 2007; 7:4-7.

12. Dobbins M, Jack S, Thomas H, Kothari A. Public health decision-makers' informational needs and preferences for receiving research evidence. Worldviews Evid Based Nurs 2007; 4:156-63.

13. Gilca V, Sauvageau C, McNeil S, Gemmill IM, Dionne M, Dobson S, et al. Setting priorities for new vaccination programs by using public health officers and immunization managers opinions. Vaccine 2008; 26:4204-9.

14. Rothman SM, Rothman DJ. Marketing HPV vaccine: implications for adolescent health and medical professionalism. JAMA 2009; 302:781-6.

15. Zimet GD, Shew ML, Kahn JA. Appropriate use of cervical cancer vaccine. Annu Rev Med 2008; 59:223-36. 
16. Danish Centre for Evaluation and Health Technology Assessment. Reduction in the risk of cervical cancer by vaccination against human papillomavirus (HPV): a health technology assessment. http:// www.dacehta.dk (accessed on 14/Nov/2009).

17. Piñeros M, Cortés C, Trujillo LM, Wiesner C. Conocimientos, aceptabilidad y actitudes sobre la vacuna contra el VPH en médicos generales, ginecólogos y pediatras en Colombia. Rev Colomb Cancerol 2009; 13:88-98.

18. Monk BJ, Wiley DJ. Will widespread human papillomavirus prophylactic vaccination change sexual practices of adolescent and young adult women in America? Obstet Gynecol 2006; 108:420-4.

19. Winer RL, Lee SK, Hughes JP, Adam DE, Kiviat NB, Koutsky LA. Genital human papillomavirus infection: incidence and risk factors in a cohort of female university students. Am J Epidemiol 2003; 157:218-26.

20. Margolis H, Alter M, Krugman S. Strategies for controlling hepatitis B in the United States. In: Hollinger FB, Lemon SM, Margolis HS, editors. Viral hepatitis and liver disease. Baltimore: Williams \&Wilkins; 1991. p. 720-2.

21. The Gambia Hepatitis Intervention Study. The Gambia Hepatitis Study Group. Cancer Res 1987; 47:5782-7.
22. Colgrove J. The ethics and politics of compulsory HPV vaccination. N Engl J Med 2006; 355:2389-91.

23. Field RI, Caplan AL. A proposed ethical framework for vaccine mandates: competing values and the case of HPV. Kennedy Inst Ethics J 2008; 18:111-24.

24. Haber G, Malow RM, Zimet GD. The HPV vaccine mandate controversy. J Pediatr Adolesc Gynecol 2007; 20:325-31.

25. Franco EL, Harper DM. Vaccination against human papillomavirus infection: a new paradigm in cervical cancer control. Vaccine 2005; 23:2388-94.

26. Franco EL. Commentary: health inequity could increase in poor countries if universal HPV vaccination is not adopted. BMJ 2007; 335:378-9.

27. Shefer A, Markowitz L, Deeks S, Tam T, Irwin K, Garland SM, et al. Early experience with human papillomavirus vaccine introduction in the United States, Canada and Australia. Vaccine 2008; 26 Suppl 10:K68-75.

28. Ugalde A, Homedes N. Descentralización del sector salud en América Latina. Gac Sanit 2002; 16: 18-29.

Submitted on $26 / \mathrm{Jan} / 2010$

Approved on 24/Mar/2010 